\title{
Pulmonary and disseminated tubercular disease by Bacillus of Calmette-Guérin after administration as a local adjuvant immunotherapy of relapsing bladder adenocarcinoma
}

\author{
Roberto Manfredi, Nicola Dentale \\ From $16^{\text {th }}$ International Symposium on HIV and Emerging Infectious Diseases \\ Marseille, France. 24-26 March 2010
}

\section{Background}

Aim of our work is to present two exemplary cases of patients ( $p$ ) who received a prolonged intravesical immunotherapy with instillations of Bacillus of Calmette-Guérin (BCG), to treat an urothelial carcinoma of the bladder relapsing after endoscopic-surgical treatment, who suffered from a severe pulmonary infection caused by Mycobacterium bovis. Their diagnostic pathway was particularly cumbersome due to the co-existing chronic pulmonary diseases (COPD), and prior respiratory disorders (including a juvenile tuberculosis). The second presented $\mathrm{p}$ was also interested by a genito-urinary (penile) localization of BCG infection, to attribute to local BCG dissemination.

\section{Methods}

Both p (aged 77-58 years, respectively), had radiological remnants of a prior tubercular infection, concurrently with a severe BPCO (at HRCT scan). Histopathologic studies showed granulomatous-necrotizing lesions with a diffuse macrophage, histiocyte, and giant cell infiltrate, followed by endoalveolar fbrosis in the second patient. No mycobacteria were detected at microscopy-culture, as well as after polymerase chain reaction (PCR) assays.

\footnotetext{
* Correspondence: Roberto.manfredi@unibo.it
}

Infectious Diseases, S. Orsola Hospital, Bologna, Italy

\section{Results}

Our first $\mathrm{p}$ had a mild positive Mantoux intradermal reaction while he tested frankly positive at the interferon-gamma release assay (IGRA), thus representing the first case of BCG-itis diagnosed also with the aid of these recent techniques. From a clinical point of view, the miliary-nodular-infiltrative picture of the first $\mathrm{p}$, and the granulomatous-fibrosing aspects of the second p, showed a slow but progressive ameliorement during anti-tubercolar therapy, but the long-term follow-up detected a persisting worsening of respiratory function parameters in the second $\mathrm{p}$. When discussing the potential pathogenetic correlates between BCG intravesical immunotherapy of bladder carcinoma and pulmonary and lung-urogenital disease localizations, after careful exclusion of other ethiologies we have no doubt in attributing these complications to BCG, even in the absence of bacterial isolation, just because the antigenic load itself caused by repeated instillations of a live, attenuated M. bovis strains (BCG) is a condition sufficient to trigger a pulmonary and systemic disease, and drive its subsequent evolution.

\section{Discussion}

To our knowledge, only four cases of respiratory BCGitis have been reported to date (as simil-tubercular forms), two of them after periodical intravesical BCG instillations, in $\mathrm{p}$ with relapsing urothelial cancer. The second presented $\mathrm{p}$ represents the first case interested by a dual, concurrent granulomatous BCG infections, involving both genito-urinary and lower respiratory 
tract. Particular attention should be taken by Urologists, Internal Medicine, and Infectious Diseases specialists in collecting the history and in monitoring patients who undergo adjuvant BCG immunotherapy.

Published: 11 May 2010

doi:10.1186/1742-4690-7-S1-P91

Cite this article as: Manfredi and Dentale: Pulmonary and disseminated tubercular disease by Bacillus of Calmette-Guérin after administration as a local adjuvant immunotherapy of relapsing bladder adenocarcinoma. Retrovirology 2010 7(Suppl 1):P91.

Submit your next manuscript to BioMed Central and take full advantage of:

- Convenient online submission

- Thorough peer review

- No space constraints or color figure charges

- Immediate publication on acceptance

- Inclusion in PubMed, CAS, Scopus and Google Scholar

- Research which is freely available for redistribution

Submit your manuscript at www.biomedcentral.com/submit 